\section{Krzysztof Brenskott}

Uniwersytet Jagielloński

\title{
Jak czytać planszówki? Gry planszowe zorientowane na narrację a powieści hipertekstowe
}

\section{Abstract \\ How to Read Board Games: The Similarities between Narrative- -Oriented Board Games and Hypertext Novels}

In Storytelling in the Modern Board Game: Narrative Trends from the Late 1960s to Today, Marco Arnaudo describes how board games can create narratives by using the tools that ludology and postclassical narratology provide. The way narratives emerge from tabletop games is extremely unique and interactive: they are created through the synergy of the game rules, material components, and actions undertaken by players. Board games, treated as transmedial narrative systems in which the text is entangled in various relations with images, sounds, or the ludic aspects of games, can become an area of research in literary studies. The aim of this paper is to demonstrate that a scholar can effectively use knowledge of hypertext novels or ergodic literature to study narrative-oriented board games.

Słowa kluczowe: gry planszowe, narratologia, powieść hipertekstowa, literatura ergodyczna, ludologia

Keywords: board games, narratology, hypertext novel, ergodic literature, ludology 


\section{Wstęp}

Gry wideo coraz częściej stają się przedmiotem analiz w polskich pracach literaturoznawczych, na co wskazuje choćby wydanie w ostatnich latach takich monografii, jak Gry wideo. Zarys poetyki $i^{1}$ Piotra Kubińskiego, Update. Teorie i praktyki kultury gier komputerowych ${ }^{2}$, Hermeneutyka gier wideo ${ }^{3}$ Michała Kłosińskiego czy Dyskursy gier wideo ${ }^{4}$. Zainteresowanie to nie przekłada się jednak, jak można by było się spodziewać, na gry analogowe, które na pierwszy rzut oka wydają się mieć więcej wspólnego z tradycyjnym przedmiotem badań literaturoznawczych. Być może wiąże się to z błędnym przekonaniem, że gry planszowe, kojarzone zapewne z produktami takimi jak Chińczyk i Eurobiznes, nie potrafią wytworzyć narracji godnej akademickiej uwagi. Nic bardziej mylnego - nowoczesne gry planszowe zorientowane na narrację mogą stanowić wyzwanie warte podjęcia. Trud związany z zapuszczaniem się na obce terytorium może być wynagrodzony odkryciem, że rozważania akademickie omijają dość obszerną (i coraz popularniejszą) kategorię tekstów. Ich specyfika nie powinna być przeszkodą, a zachętą do podejmowania badań, tym bardziej że w obrębie literaturoznawstwa funkcjonują już terminy pozwalające tę specyfikę uchwycić. Niniejszy tekst jest próbą wykazania, że literaturoznawca zaznajomiony $\mathrm{z}$ gatunkiem powieści hipertekstowej i koncepcjami takimi jak literatura ergodyczna, może tę wiedzę w sposób skuteczny zaaplikować do badań nad coraz popularniejszymi rodzajami tekstów: grami planszowymi, i że te ostatnie (a przynajmniej niektóre z nich) mogą być czytane jak powieści hipertekstowe.

\section{Transmedialny system narracyjny - czym jest gra planszowa i jak wytwarza narrację?}

Teoretycy cybertekstu, hipertekstu i literatury ergodycznej zwracają uwagę na znaczącą rolę medium (godząc się nawet $\mathrm{z}$ oskarżeniami o nadmierne „esencjalizowanie”, co podkreślała Katherine Hayles, odpowiadając Marrku Eskelinenowi ${ }^{5}$ ), którego cechy decydują o specyfice takich utworów. Gra

${ }^{1}$ P. Kubiński, Gry wideo. Zarys poetyki, Kraków 2016.

${ }^{2}$ Update. Teorie i praktyki kultury gier komputerowych, red. Ł. Androsiuk, Lublin 2017.

${ }^{3}$ M. Kłosiński, Hermeneutyka gier wideo. Interpretacja, immersja, utopia, Warszawa 2018 .

${ }^{4}$ Dyskursy gier wideo, red. M. Kłosiński, K. Maj, Kraków 2019.

5 K. Hayles, What Cybertext Theory Can't Do, ,Electronic Book Review” 2001, http:// electronicbookreview.com/essay/what-cybertext-theory-cant-do/ [dostęp:10.10.2020]. 
planszowa oczywiście nie może być rozumiana jako medium per se, lecz stanowi - powtarzając za Aleksandrą Mochocką i Michałem Mochockim „transmedialny system narracyjny”. Badacze opisali w ten sposób gry RPG, jednak zaproponowany przez nich termin wydaje się równie adekwatny w stosunku do gier planszowych nastawionych na tworzenie opowieści (story-driven games). Gry planszowe są w istocie skomplikowanym systemem, na który składają się różne elementy oraz - co istotne - interakcje zachodzące między tymi elementami. Oznacza to, że dana gra jest czymś więcej niż tylko sumą wykorzystanych elementów. Jak pisze Marcin Petrowicz:

[...] system rozgrywki nie jest zaledwie zbiorem jego składników. Gry wykazują się emergencją: proste elementy, wchodząc ze sobą w interakcje, tworzą złożone systemy rozgrywki, których nie można zredukować do sumy tychże elementów?

Petrowicz do opisu gier wykorzystuje koncepcję formalnego zamkniętego systemu zasad, którą pożycza od Katie Salen i Erica Zimmermana. Spojrzenie na gry planszowe z perspektywy ludologicznej pozwala uchwycić ich specyfikę jako gier właśnie, a więc zwraca uwagę nie na prezentowane treści, czym zajmuje się w game studies narratologia, lecz na samo medium. „W tej perspektywie przedmiotem analizy jest gra rozumiana jako zestaw elementów, reguł i właściwości" - powtórzmy za Petrowiczem. Sięgając po wypracowany przez Robin Hunicke, Marca LeBlanca i Roberta Zubeka model MDA, badacz dzieli system gry na: mechaniki, które za Mochocką można rozumieć jako „zespół zasad operacyjnych nadbudowanych na zasadach konstytutywnych, regulujący działanie systemu gry i możliwe działania graczy", dynamiki, definiowane jako ,powtarzalna seria interakcji, w jaką wchodzą ze sobą mechaniki i zasady rozgrywki” ${ }^{10}$, i doznania, a więc „emocjonalne odczucia, jakie gra wzbudza podczas rozgrywki" ${ }^{11}$. Innymi słowy: skodyfikowane zasady rozgrywki tworzą statyczne mechaniki (,zaprojektowane reguły interakcji”"12), z których wynikają powtarzalne pętle interakcji, uruchamiane najczęściej przez gracza

${ }^{6}$ A. Mochocka, M. Mochocki, Tabletop RPG: transmedialny system narracyjny [w:] Narratologia transmedialna. Teorie, praktyki, wyzwania, red. K. Kaczmarczyk, Kraków 2017, s. 337-391.

${ }^{7}$ M. Petrowicz, Dynamiki w grach - definicje i wykorzystanie w analizie, „Teksty Drugie" 2017, nr 3, s. 178.

8 Ibidem, s. 180.

9 A. Mochocka, Polskie gry planszowe oparte na utworach literackich - rekonesans, „Biblioteka Postscriptum Polonistycznego” 2015, nr 5, s. 42.

${ }^{10}$ M. Petrowicz, Dynamiki w grach..., s. 185.

11 Ibidem, s. 182.

${ }_{12}$ M. Petrowicz, Zasady przeciw immersji. Zaangażowanie $w$ narrację $i$ zaangażowanie w system formalny gry, „Replay. The Polish Journal of Game Studies” 2015, nr 1(2), s. 40. 
i aktualizujące się w trakcie gry, czyli dynamiki. Te ostatnie, odpowiadając za przebieg rozgrywki, oddziaływają na doznania graczy. Tak opisywany system formalny jest dla badacza systemem emergentnym (Petrowicz sięga do pracy Rules of Play Salen i Zimmermana), a więc takim, w którym dodawanie kolejnych elementów „Zwiększa złożoność w sposób nielinearny”13, co wynika z przyjętego modelu MDA - jeżeli podstawą gry planszowej są interakcje między elementami i pętle interakcji, to wnioski nasuwają się same: wprowadzenie jednego nowego elementu generuje szereg interakcji ze wszystkimi innymi elementami. Ściśle ludologiczne spojrzenie na grę planszową pozwala zrozumieć, z jak ciekawym, niedającym się sprowadzić do planszy i kart, fenomenem mamy do czynienia. Nasuwa się pytanie o to, jak w takim środowisku może realizować się hipertekstowy utwór literacki.

Pomocy w odpowiedzi na to pytanie mogą udzielić rozważania Mochockiej, która - choć również czerpie z modelu MDA - zaprzęga do opisu tego, czym są gry planszowe, narzędzia literaturoznawcze:

Nowoczesne gry planszowe są skomplikowanymi systemami, które z jednej strony stanowią mechanizm umożliwiający rozgrywkę, z drugiej zaś są pewnym zespołem znaków, które tworzą komunikat nawet wtedy, gdy nie zostaje uruchomiony tzw. gameplay ${ }^{14}$.

Dostrzeżenie przez Mochocką w grze zarówno systemu, umożliwiającego rozgrywkę, jak i zespołu znaków, który może znaczyć, jest o tyle istotne, że pozwala gry planszowe analizować już nie tylko ze względu na ich formę, lecz także przez tworzony w ich obrębie komunikat. Badaczka wykorzystuje utrakwistyczną teorię dramatu, według której równoprawny jest zarówno odbiór przedstawienia teatralnego wygrywanego na scenie, jak i odbiór samego zapisu tekstu werbalnego ${ }^{15}$.

Choć Mochocka dostrzega znakowy charakter gry, to uważa, że jest on wtórny bądź podporządkowany rozgrywce ${ }^{16}$, wikłając się tym samym w fałszywy spór między ludologią a narratologią. Wiele gier planszowych, w tym tych najwyżej ocenianych na portalu boardgamegeek.com (choćby Gloomhaven, This War of Mine, T.I.M.E Stories i Arkham Horror: The Card Game), nie tworzy narracji tylko po to, by usprawiedliwić mechaniki, ale do tego zagadnienia wrócimy. Na razie zatrzymajmy się na chwilę przy propozycji Mochockiej. Badaczka wymienia pozajęzykowe i językowe elementy gry planszowej (warstwę fizyczną, szatę graficzną, przekaz werbalny), elementy ludyczne (zasady gry) i niematerialny komponent gry, czyli gameplay ,powstający na

\footnotetext{
13 Idem, Dynamiki w grach..., s. 181.

${ }^{14}$ A. Mochocka, Polskie gry planszowe..., s. 39.

15 Ibidem, s. 39-40.

16 Ibidem, s. 39-43.
} 
styku wszystkich tych [...] elementów"17. Rozważania te rozbudowuje, wykorzystując klasyfikację przestrzeni książki Andrzeja Dróżdża: gra w tym ujęciu posiada więc zewnętrzną przestrzeń trójwymiarową (ciężar, wielkość etc.), zewnętrzną przestrzeń dwuwymiarową (elementy typograficzne, ilustracje znajdujące się na kartach, na pudełku, w instrukcji etc.) oraz przestrzeń wewnętrzną, czyli zasady gry i nadbudowany na nich gameplay ${ }^{18}$. Ujęcie badaczki uzupełnia wiedzę o działaniu gry, którą czerpiemy z modelu MDA, o dodatkowe warstwy, lub - jak woli Mochocka - przestrzenie. Mechaniki i dynamiki stanowić będą bowiem tylko przestrzeń wewnętrzną - fenomen gry zostaje więc poszerzony o namysł nad wykorzystywanymi przez system mediami (ilustracje, tekst etc.). Ujawnia to skrajnie transmedialny charakter systemu, jakim jest gra planszowa.

Świadomość sposobu działania medium to jedno. Czym innym jest pytanie o możliwość budowania narracji przez gry planszowe. Wydana w 2018 roku książka Marco Arnaudo Storytelling in the Modern Board Game w sposób kompleksowy omawia to zagadnienie. Badacz - wykorzystując zdobycze ludologii i narratologii postklasycznej - pokazuje, w jaki sposób gry opowiadają historie (storytelling) i jakie rodzaje opowieści są w stanie wytworzyć. Narracja, zdaniem Arnaudo, powstaje poprzez synergię zasad gry, materialnych komponentów i działań podejmowanych przez gracza ${ }^{19}$ - opowieść ta jest dynamiczna i rozwija się w trakcie rozgrywki. Wymienia on warunki, jakie muszą być spełnione, by gra mogła „opowiedzieć historię”:

- musi być obecna treść (content);

- zasady i mechaniki powinny odzwierciedlać podstawowe dynamiki tego, co gra ma przedstawiać;

- treść i mechaniki muszą współpracować przy tworzeniu spójnego świata, w którym osadzona będzie rozgrywka;

- wydarzenia przedstawione w trakcie rozgrywki łączą się ze sobą poprzez relację przyczynową;

- gracze powinni kontrolować konkretne, unikatowe postaci, z którymi mogą się identyfikować;

- postaci, którymi kierują gracze, muszą mieć wyznaczone cele;

- postaci, którymi kierują gracze, muszą przechodzić jakąś formę przemiany w trakcie rozgrywki;

- strategie wykorzystywane przez graczy powinny odpowiadać strategiom, które wybrałyby ich postaci w świecie gry;

17 Ibidem, s. 40.

18 Ibidem, s. 42.

${ }_{19}$ M. Arnaudo, Storytelling in the Modern Board Game: Narrative Trends from the Late 1960s to Today, Jefferson, NC 2018, s. 8. 
- gra jest zaprojektowana tak, by pozostawić pewną dozę niepewności co do treści i opcji, które będą dla graczy dostępne podczas danej sesji, osiągając w ten sposób progresywne odkrywanie kolejnych elementów fabuły $^{20}$.

Jeżeli gra spełnia większość z tych wymogów, to zapewni graczom grywalne, interaktywne doświadczenie narracyjne ${ }^{21}$, a więc coś, czego dostarczyć może także powieść hipertekstowa. Według Anne Sullivan i Anastasii Salter w grach planszowych budujących narrację udział biorą takie elementy, jak: wydarzenia (mające konsekwencje jednocześnie dla mechanik gry i tworzonej narracji), agenci (rozumiani jako reprezentacja gracza w przestrzeni gry), obiekty, czas (ze względu na odbywający się w turach system rozgrywki, czas decyduje o ograniczeniach sposobów, w jakie gra planszowa tworzy narrację), a w końcu przestrzeń, bo plansza (lub zestaw kart, kafelków etc., odgrywających rolę planszy) to metafora relacji przestrzennych, jakie panują w świecie gry ${ }^{22}$.

W przypadkach gier zorientowanych na tworzenie narracji trudno odróżnić grę rozumianą jako formalny system zasad od gry rozumianej jako system znaków, ponieważ tworzenie narracji jest elementem wynikającym z zasad, i to często elementem kluczowym - zasady są zaprojektowane w ten sposób, by umożliwić powstawanie opowieści. Forma i treść idą ramię w ramię, a treść staje się gameplayem. Mochocka zastanawiała się nad tym, czy czytanie tekstu werbalnego gier bez uruchamiania samej rozgrywki jest możliwe, tak jak w przypadku dramatu. W grach zorientowanych na narrację rozgrywka jest ich lekturą - jeżeli chciałoby się sięgnąć po przykład ze świata literatury, to dramat nie jest najtrafniejszy. Dlaczego? Ponieważ zapisany tekst werbalny dramatu pozostaje klasycznym tekstem. Nie jest interaktywny, a jego treść nie wyłania się z decyzji podejmowanych przez czytelnika/użytkownika, nadzorowanych i udostępnianych przez przygotowany do tego program czy zbiór zasad. Można go przeczytać w sposób linearny i jego przekaz nadal jest zrozumiały, co nie jest możliwe w wypadku gier zorientowanych na narrację, gdyż dostarczają one wielu alternatywnych sposobów rozwoju narracji, z których treść wyłania się dopiero poprzez odpowiednie ich połączenie. Jon Dovey i Helen W. Kennedy zauważają, że tekst byłby w grze rozumiany jako, ,złożona interakcja pomiędzy graczem a grą, określana mianem rozgrywki (ang. gameplay)"23. Zwróćmy jednak uwagę na coś niezwykle istotnego: nie jest to

${ }^{20}$ Ibidem, s. 27-43.

${ }^{21}$ Ibidem, s. 43.

${ }^{22}$ A. Sullivan, A. Salter, A Taxonomy of Narrative-centric Board and Card Games [w:] Proceedings of the $12^{\text {th }}$ International Conference on the Foundations of Digital Games, eds. A. Canossa et al., New York 2017, s. 2, https://dl.acm.org/citation. cfm?id=3102071.3102100 [dostęp: 10.01.2020].

23 J. Dovey, H.W. Kennedy, Kultura gier komputerowych, przeł. T. Macios, A. Oksiuta, Kraków 2011, s. 7. Podkr. autorzy. 
różnica wynikająca z tego, że jedne utwory są sieciowe, a inne drukowane - o fałszywości takiego podziału świadczą te utwory Laurence'a Sterne'a, Jamesa Joyce'a czy Jorge Luisa Borgesa, które George P. Landow nazywał „quasi-hipertekstowymi”24, a Jay D. Bolter uważał za w pełni hipertekstowe ${ }^{25}$. Nie chodzi więc tylko o cyfrowy bądź analogowy charakter, lecz o strukturę tekstu i sposób wykorzystania medium - pamiętajmy, że gry planszowe też w większości ${ }^{26}$ składają się z elementów fizycznych.

\section{Powieści hipertekstowe i gry planszowe nastawione na narrację jako dzieła ergodyczne}

Dużo bliższe grom planszowym są powieści hipertekstowe, w których aktywne uczestnictwo również jest jedyną możliwą formą ich lektury i w których nie da się zignorować roli medium, jeżeli chce się w pełni zrozumieć narrację. Grę planszową lepiej porównać zatem nie do dramatu, lecz do literatury ergodycznej.

Czym ona jest? Jak pisze Espen J. Aarseth: „,[d]zieła ergodyczne wymagają nietrywialnego wysiłku i dopiero on pozwala czytelnikowi przechodzić przez tekst" ${ }^{\prime 2}$. Zaliczenie gier wideo w poczet dzieł ergodycznych nie budzi większych wątpliwości - pisze o tym chociażby Marcin Pisarski, zauważając, że gry, podobnie jak hiperteksty, ,zapraszają czytelnika do wykonania «nietrywialnego wysiłku», czyli na przykład uruchamiania mechanizmu, na którym osadzono tekst" ${ }^{28}$. Gry analogowe nie powinny być traktowane inaczej: Arnaudo opisuje je przecież jako „leniwe maszyny, które wykonują swą pracę dopiero wtedy, gdy gracze aktywnie manipulują ich fizycznymi komponentami”"29. Według Pisarskiego ,[i] w grze, i w hipertekście narracja jest ergodycznie wyprodukowaną sekwencją zdarzeń" ${ }^{30}$. Co badacz przez to rozumie?

${ }^{24}$ G.P. Landow, Hypertext. The Convergence of Contemporary Critical Theory and Technology, Baltimore, ML 1992, s. 108.

25 J.D. Bolter, Writing Space. Computers, Hypertext, and the Remediation of Print, Hillsdale, NJ 1991, s. 135.

${ }^{26}$ Do niektórych gier wymagane jest posiadanie aplikacji towarzyszącej, por.: Posiadtość Szaleństwa (druga edycja) czy Władca Pierścieni: Podróże przez Śródziemie.

27 E.J. Aarseth, Cybertekst: Perspektywy literatury ergodycznej. Wstęp: Literatura ergodyczna, przeł. D. Sikora, M. Pisarski, „Techsty” 2006, nr 2, http://techsty.art.pl/magazyn2/artykuly/aarseth_cybertekst.html [dostęp: 10.01.2020].

${ }^{28}$ M. Pisarski, Ergodyczność, http://www.techsty.art.pl/hipertekst/teoria/ergodyzm.htm [dostęp:10.01.2020].

${ }^{29}$ M. Arnaudo, Storytelling in the Modern..., s. 9.

${ }_{30}$ M. Pisarski, Hipertekst a gry komputerowe, http://www.techsty.art.pl/hipertekst/gry. htm [dostęp: 10.01.2020]. 
Narracja ergodyczna zasadza się na polu zdarzeń: bazie narracyjnych możliwości, która składa się z napisanych przez autora wariantów fabuły (czasami warianty te dopisywać może sam czytelnik). Ich pojawianie się na ekranie uzależnione jest od poszczególnych kroków lektury czytelnika i wpisanego w tekst mechanizmu [...]. Nie ma zatem jednej narracji, jest płynna, zmieniająca się i różnicująca multinarracja ${ }^{31}$.

Wyciągnięcie wszystkich leksji ${ }^{32} \mathrm{z}$ utworu hipertekstowego i wklejenie ich do edytora tekstu nie jest w żadnym wypadku tożsame z zapoznaniem się z tym utworem, bo łącza i sekwencje leksji są jego strukturalnymi elementami - podobnie jak w przypadku gier, powieści hipertekstowe nie są sumą elementów, a ich istota tkwi w interakcjach między tymi elementami. Nieprzypadkowo Arnaudo pisze o narracyjnym doświadczeniu (narrative experience). Lektura powieści hipertekstowej i lektura narracji wyłaniającej się z gry Horror w Arkham jest interaktywnym doświadczeniem. Jak pisze Elżbieta Winiecka:

Hipertekstowość to [...] strukturalna właściwość tekstu, a nie lekturowa strategia. Ta druga jest konsekwencją pierwszej. Kliknięcie w link jest aktem jedynie pozornego wyboru kolejności następujących po sobie fragmentów, których łączliwość została przewidziana już na etapie autorskiego projektu ${ }^{33}$.

Nie chodzi więc o całkowitą dowolność czytelnika w nawigowaniu po tekście, a o wolność ograniczaną autorską wizją - wszystkie możliwe narracje, wyłaniające się z powieści hipertekstowej, są przewidziane przez jego twórcę/ twórców. John E. McEneaney zauważa, że to nie czytelnik decyduje o tym, jaką część tekstu przeczyta w jakiej kolejności, a program nadzorujący lekturę i udostępniający odbiorcy możliwe wybory ${ }^{34}$ - w przypadku gier wideo i wirtualnych hipertekstów byłby to kod, w przypadku gier planszowych instrukcje, księgi zasad i księgi scenariuszy.

Podobnie jest w grach planszowych zorientowanych na narracje: jak pisze Arnaudo, ich elementy zawierają każdy możliwy wariant finalnej opowieści ${ }^{35}$ (porównajmy to z: „hipertekst ma strukturę pola zdarzeń (event space),

${ }^{31}$ M. Pisarski, Poetyka: narracja w hipertekście, http://www.techsty.art.pl/hipertekst/ poetyka/narracja.htm [dostęp:10.01.2020].

${ }^{32}$ Leksje - podstawowe jednostki w hipertekście. W dalszej części będziemy je dokładniej opisywać.

${ }^{33}$ E. Winiecka, Poszerzanie pola literatury w ,, Tajemniczym płomieniu królowej Loany” Umberta Eco, „Zagadnienia Rodzajów Literackich” 2015, z. 2, s. 103.

${ }_{34}$ J.E. McEneaney, Toward a Post-Critical Theory of Hypertext, http://citeseerx.ist.psu. edu/viewdoc/download?doi=10.1.1.25.7028\&rep=rep1\&type=pdf [dostęp: 10.10.2020].

${ }_{35}$ M. Arnaudo, Storytelling in the Modern..., s. 20. 
w którym zawierają się wszystkie warianty opowiadania" $\left.{ }^{36}\right)$. Do hipertekstowych struktur Winiecka odnosi jeden z rodzajów interaktywności wyróżnionych przez Erica Zimmermana, czyli interaktywność eksplicytną, strukturalną, która „,dotyczy zaprojektowanych w dziele wyborów, których czytelnik musi dokonywać, jeśli chce czytać dalej" ${ }^{37}$. Tak samo przebiega rozgrywka w przywoływaną wcześniej grę Horror w Arkham. Przykładowo w scenariuszu Zgromadzenie gracz musi wybrać, czy chce przed ucieczką spalić swój dom. Od decyzji zależy przebieg dalszych rozgrywek. Oba możliwe wybory zostały tak zaprojektowane, by zmodyfikować dalsze scenariusze - gracz ma wolność wyboru, ale wolność pozorną, ponieważ nie może zdecydować, że pozostanie w domu i nie wyruszy w dalszą podróż (Winiecka: „Oznacza to, że akt odbioru zaprojektowanego przez pisarza utworu jest każdorazowo działaniem, w trakcie którego odbiorca fizycznie angażuje się w proces wyłaniania dzieła" ${ }^{38}$ ). Gracz może sobie - co najwyżej - wyobrazić taki wariant i zrezygnować z dalszej rozgrywki. Jeżeli jednak chce kontynuować „lekturę", musi zaakceptować zasady gry i - poprzez swoje działania i wybory - brać udział w wyłanianiu się jednej możliwej wersji narracji: jeżeli weźmiemy pod uwagę liczbę zmiennych, jakie mogą wpłynąć na rozwój narracji (wymieńmy choćby różnorodność bohaterów, dziesiątki wyborów dalszej ścieżki, wydarzenia wyzwalane przez zaistnienie odpowiednich warunków w grze), to jasne stanie się, iż mamy do czynienia $\mathrm{z}$ wieloma wariantami tego samego utworu. Dlatego też Landow pisał o hipertekście, że lepiej niż „nielinarny” charakteryzują go takie przymiotniki, jak „,multilinearny i wielosekwencyjny" ${ }^{39}$ - przymiotniki te opisują również gry planszowe będące przedmiotem naszej refleksji.

Co więcej, jak przekonuje Isaac Karth, w narracjach ergodycznych czytelnik napotyka przeszkody i bariery, które musi pokonać, żeby móc dotrzeć do kolejnych części tekstu ${ }^{40}$ - przeszkody przewidziane i zaplanowane przez twórców utworu. Jest to oczywiście mechanizm inny niż różne interpretacje, bo polega na interaktywnej ingerencji w samą treść, a nie jej zrozumienie. W ujęciu Pisarskiego wygląda to następująco:

${ }^{36}$ E. Winiecka, Czytanie jako działanie, dzieło jako zdarzenie. Czy możliwa jest poetyka literatury interaktywnej?, „Poznańskie Studia Polonistyczne. Seria Literacka” 2017, nr 30, s. 203-204.

37 Ibidem, s. 195.

${ }^{38}$ Ibidem, s. 205.

${ }^{39}$ G.P. Landow, Hypertext as Collage-Writing [w:] The Digital Dialectic: New Essays on New Media, ed. P. Lunenfeld, Cambridge, MS-London 1999, s. 154.

${ }^{40}$ I. Karth, Ergodic Agency: How Play Manifests Understanding [w:] Engaging with Videogames: Play, Theory and Practice, eds. D. Stobbart, M. Evans, Leiden 2019, s. 208. 
Rozwidlenia nie mają [...] charakteru przenośnego, nie wskazują na sferę mentalną czy interpretacyjną, lecz na poziom świata przedstawionego, na sferę narracji oraz odniesień intertekstualnych, gdzie udosławniają, materializują czy też dramatyzują potencjał odesłań i rozgałęzień od zawsze obecny w tekście (w ogólności) i w procesie opowiadania (w szczególności). ${ }^{41}$

Warto też pamiętać, że w narracji ergodycznej system nie jest pasywny i reaguje na działania czytelnika/gracza ${ }^{42}$.

Przywołane poniżej słowa Winieckiej dają się odnosić zarówno do hipertekstu, jak i do gier planszowych zorientowanych na narrację:

Wydarzenie, jakim staje się każdorazowo odbiór dzieła, jest procesem jednorazowym i jeszcze bardziej złożonym niż akt interpretacji dzieła literackiego. Nowa mechanika tekstu nie wypiera wszak dawnej aktywności czytelniczej, dodaje do niej za to kolejne płaszczyzny (wymiary) ${ }^{43}$.

Jeszcze raz przypomnijmy, że Arnaudo każdorazowo pisze o „doświadczeniu narracyjnym", które byłoby tym samym, czym omawiane przez Winiecką wydarzenie - oba wyrażenia podkreślają jednorazowość i interaktywność każdorazowego procesu odbioru.

\section{Analiza gry Horror w Arkham}

Zauważenie tych podobieństw, na razie dość ogólnych, zachęca do komparatywnej analizy. Spróbujmy, korzystając z kroków, które powinien podjacć badacz powieści hipertekstowych według Mariusza Pisarskiego, przeanalizować Horror w Arkham jako pewną realizację hipertekstu, nie spuszczając z oczu jej specyfiki jako gry planszowej ${ }^{44}$. Propozycja badacza zakłada, że najpierw należy „określić struktury, jakimi utwór się posługuje"45, a więc, czy jest to hipertekst osiowy, drzewiasty, sieciowy i tak dalej. Odpowiedź na to pytanie zależy od tego, jak funkcjonują w utworze leksje, i jest to problem, przy którym trzeba się na chwilę zatrzymać. Skąd pewność, że w przypadku

${ }^{41}$ M. Pisarski, Xanadu. Hipertekstowe przemiany prozy, Kraków 2013, s. 11.

${ }^{42}$ I. Karth, Ergodic Agency..., s. 208.

43 E. Winiecka, Czytanie jako działanie..., s. 200.

44 Horror w Arkham: Gra karciana jest - wbrew nazwie - praktycznie grą planszową, gdyż posiada element przestrzenny, a więc planszę gry. Ma ona charakter modularny i jest konstruowana z kart pomieszczeń, po których poruszają się (reprezentowane również przez karty) postaci i potwory.

${ }^{45}$ M. Pisarski, Xanadu. Hipertekstowe przemiany..., s. 227. 
gier planszowych nastawionych na narracje można w ogóle mówić o leksjach? Przywołajmy definicję hipertekstu, sporządzoną przez Pisarskiego: „Hipertekst to tekst, który rozgałęzia się i działa na żądanie czytelnika. Składają się nań połączone odsyłaczami segmenty tekstu, które mogą być wzbogacone obrazem, dźwiękiem, elementami filmowymi" ${ }^{\prime 4}$. Za leksje uważa się właśnie te połączone odsyłaczami segmenty tekstu, zwane przez badacza również najmniejszymi samodzielnymi jednostkami, węzłami, a w końcu „ogniwem tekstu połączonym w sieć z innymi ogniwami” ${ }^{` 7}$. Termin ten został zaczerpnięty z pism Rolanda Barthes'a, ale jego znaczenie w teorii hipertekstu uległo znacznemu przekształceniu.

Leksje, mogące przybierać postać paragrafu tekstowego, łączą się ze sobą (poprzez łącza), tworząc w ten sposób sieć ${ }^{48}$. Ujawniają się zatem dwie ich cechy: łączliwość i jednoczesna autonomiczność. Muszą znaczyć, ale ich głównym przeznaczeniem jest kierowanie ku kolejnym ogniwom (,,będąc punktem wyjścia, fragment $w$ hipertekście nie jest punktem dojścia. Odgrywa rolę nici Ariadny, prowadzącej do jednej z możliwych całości” ${ }^{49}$ ). Hipertekstowa lektura, jak pisze Pisarski, nadbudowuje się na trzech leksjach: „źródłowej leksji A (skąd przyszliśmy), aktualnej leksji B (gdzie się obecnie znajdujemy) oraz docelowej leksji C (dokąd przeniesieni zostaniemy po aktywacji łącza)"50. Treść dzieła wyłania się dopiero w trakcie nawigacji przez kolejne ogniwa i łańcuchy, nie istnieje zaś samoistnie. Powtórzmy za badaczem: „tytuł leksji docelowej to pierwszy element, który trzeba wziąć pod uwagę po znalezieniu się w nowym miejscu" "51. Ogniwa jawią się więc nam jako paragraf tekstowy (ale nie tylko), oznaczony nazwą, łączący się z leksjami źródłowymi i docelowymi, a w końcu zawierający hiperłącze, umożliwiające przechodzenie z jednego ogniwa do drugiego. Jak się okazuje, tak zdefiniowane i rozumiane leksje są podstawowym budulcem scenariuszy w grze Horror w Arkham. Przyjrzyjmy się scenariuszowi Widmo prawdy, będącemu piątym scenariuszem rozgrywanym w ramach kampanii Szlak do Carcosy. Otwierając instrukcję, przeczytamy:

Sprawdź dziennik kampanii. Jeżeli Król zebrał krwawe żniwo, przeczytaj Wprowadzenie 1 .

W przeciwnym wypadku przejdź do Wprowadzenia $2^{52}$.

${ }^{46}$ Ibidem, s. 18. Definicja częściowo powtórzona za Noahem Wardripem-Fruinem [przyp. red.].

${ }^{47}$ Ibidem, s. 18, przyp. 25.

48 Ibidem, s. 172.

49 Ibidem, s. 105.

50 Ibidem, s. 56.

${ }^{51}$ Ibidem, s. 187.

${ }^{52}$ Horror w Arkham: Gra karciana. Widmo prawdy, Galakta 2017. 
„Wprowadzenie 1" i „Wprowadzenie 2" to tytuły leksji, do których gracz zostaje przekierowany. Łącze wyzwalają polecenia „przejdź do" i „,przeczytaj”, wskazujące od razu konkretny kierunek. To, do której leksji trafi czytelnik, zależy od spełnionego w poprzednich scenariuszach warunku, stąd konieczność sprawdzenia w dzienniku kampanii, czy „Król zebrał krwawe żniwo”. Interaktywność w tym przypadku pojawia się, lecz w sposób pośredni - działania gracza decydują o kształcie narracji, ale są one zależne od podjętych wcześniej, a nie w tym momencie, decyzji. Leksje „Wprowadzenie 1” i „Wprowadzenie 2" mają całkowicie inną treść, lecz odsyłają do kolejnej, tej samej leksji: „Sen 1". Warto zauważyć, że kotwica (wizualna forma hiperłącza) składa się już nie tylko z polecenia, ale także tekstu „nie zgub się”. Następnie, w zależności od zapisów w dzienniku kampanii, gracze są kierowani do różnych leksji o tytule „Sen”, na przykład:

Sen 2: Constance łapie cię za rękę i ciągnie na wypolerowany parkiet. „Chodź, nie wstydź się. Tę noc spędzimy tańcząc! Świętując!”.

Sprawdź Dziennik kampanii. Jeśli Król zebrat krwawe żniwo, przejdź do Snu 8.

Jeśli powyższe nie jest prawdą i jeśli przerwaliście tajne spotkanie, przejdź do Snu 3.

Jeśli zabiliście potwory na przyjęciu, przejdź do Snu 4.

Jeśli żadne z powyższych nie jest prawdą, przejdź do Snu 6.

Rozgałęzienie się narracji w wyniku wędrówki przez leksje jest w tym przykładzie widoczne. Trzeba też zwrócić uwagę na to, że poszczególne sny, czyli leksje, pojawiają się w różnych łańcuchach i tak na przykład: do „Snu 6” można zostać skierowanym ze „Snu 2" i „Snu 3”, a mimo zmieniającego się kontekstu, leksja ta musi wciąż zachować sens. Musi działać i w jednym, i drugim wariancie, co jest cechą typową dla hipertekstów (segmenty, „operując dokładnie tym samym materiałem tekstowym, znaczą zupełnie co innego w zmienionym otoczeniu sieciowym" ${ }^{53}$ ).

Co więcej: jeżeli spojrzymy na początek instrukcji do scenariusza, możemy przeczytać: „,scenariusz ten może być rozgrywany pojedynczo, w trybie samodzielnej rozgrywki, bądź może zostać połączony z innymi dodatkami z cyklu Szlak do Carcosy w celu utworzenia większej, ośmioczęściowej kampanii”" ${ }^{4}$. A więc i sam scenariusz, będący większym zbiorem leksji, posiada cechy takie, jak autonomiczność i łączliwość.

${ }_{53}$ M. Pisarski, Xanadu. Hipertekstowe przemiany..., s. 174-175.

${ }^{54}$ Horror w Arkham: Gra karciana. Widmo... 
Nie wszystkie wybory w Horrorze w Arkham są jednak zaprogramowane przez zapiski w Dzienniku kampanii (a więc poprzednie działania graczy). Po fragmencie „Sen 10” można przeczytać:

Badacze muszą wybrać jedną z opcji:

„Jak cokolwiek z tego może ci się wydawać piękne?” Przejdź do Snu 11.

„Na co ja wtaściwie patrzę?” Przejdź do Snu 12.

Wybór i uaktywnienie łącza Pisarski nazywa aktemem ${ }^{55}$ - ten element hipertekstu jest, jak się okazuje, również obecny w omawianej grze.

Podróż po leksjach „Sny” kończy się w ogniwie „Przebudzenie”, które może skierować graczy do „Przygotowania” lub „Informacji od Jordana”. Po „Informacjach od Jordana” gracz i tak zostanie odesłany do „Przygotowania”. Na podstawie swoich poprzednich decyzji może więc zostać całkowicie pozbawiony dostępu do fragmentu tekstu. Również i to jest cechą strukturalną powieści hipertekstowej:

Rozgałęzianie się tekstu sprawia, iż czytelnik, kierując swoją lekturę w jedną stronę, omija inne możliwe kierunki, mając przy tym świadomość, że pewne partie tekstu zostały pominięte. Czyni to z powieści hipertekstowej wspomnianą „niecałą całość” ${ }^{56}$.

Gracz traci tę część tekstu, ponieważ nie spełnił wymagań stawianych przez grę. Również w powieściach hipertekstowych przejścia pomiędzy ogniwami są obwarowane specjalnymi warunkami ${ }^{57}$.

Warto zauważyć, że rdzeń rozgrywki, a więc poruszanie postaci po planszy, wykonywanie akcji, zagrywanie kart etc., rozpoczyna się dopiero po przejściu do sekcji „Przygotowanie”, w której opisany jest proces przygotowania talii spotkań (a więc zagrożeń, jakie spotkają graczy w danym scenariuszu), ułożenia kart lokalizacji (a więc zbudowania planszy) etc. Zatrzymajmy się jednak na chwilę na tym etapie. Instrukcja do scenariusza wzorowana jest na grach paragrafowych, których strukturę Pisarski porównuje do drzewa ${ }^{58}$, co odsyła do jednej z trzech struktur hipertekstowych: hipertekstów drzewiastych, w których „główny pień rozdziela się na dwie lub więcej odnóg i ma tyleż możliwych zakończeń" ${ }^{59}$. Sytuacja jednak komplikuje się, gdy przejdziemy do głównej części rozgrywki.

\footnotetext{
${ }_{55}$ M. Pisarski, Xanadu. Hipertekstowe przemiany..., s. 56.

56 Ibidem, s. 91.

57 Ibidem, s. 120-121.

58 Ibidem, s. 95.

${ }^{59}$ Ibidem, s. 39.
} 
Ze względu na poziom skomplikowania analizowanego materiału i objętość niniejszego tekstu zignorujemy większość elementów ludycznych, ale warto sobie zdawać sprawę z ich istnienia: $\mathrm{w}$ trakcie rozgrywki każdy gracz wciela się w jednego badacza o unikatowych cechach, umiejętnościach i - co równie ważne! - historii. Z punktu widzenia gameplayu (nie mówiąc już oczywiście o samej narracji) przeszłość kierowanej przez nas postaci ma znaczenie, bowiem jej pewne mroczne elementy wracają w postaci unikatowej karty, wtasowanej do talii, z której korzysta gracz. I tak poprzez losowy dobór kart, odbywający się na początku każdej tury, słabość lub ciemna przeszłość bohatera mogą wyjść na jaw, znacząco mu szkodząc. Przykładowo: postać będąca weteranem wojennym może dociągnąc kartę reprezentującą wspomnienia traumatycznych wydarzeń. O byłą kultystkę upomną się inni sekciarze. Kryminalista może trafić na ścigającego go policjanta. Inna z postaci będzie musiała spłacić dług, zaciągnięty na leczenie chorej matki. Podobnie rzecz się ma z kartami spotkań, które gracze losują co turę, a które reprezentują czyhające na nich zagrożenia - czasem jest to coś tak trywialnego, jak dziura w podłożu, nierzadko są to potwory i duchy, a nawet poczucie bycia obserwowanym. Również działania wykonywane przez graczy, takie jak przeszukiwanie pomieszczenia w celu znalezienia wskazówek, pertraktacje z napotkanymi postaciami, walka z przeciwnikami etc., odbywają się poprzez wykonanie testu odpowiedniej umiejętności (gdzie porównuje się wartość liczbową danej sprawności badacza, na przykład zwinności czy siły woli z trudnością testu) oraz modyfikowanie wyników za pomocą kart i losowanych żetonów. Wszystko to ma ogromny wpływ na tworzoną lub raczej wyłaniającą się z rozgrywki - w sposób transmedialny! - opowieść.

Wróćmy jednak do elementów tekstowych i sposobu ich funkcjonowania w strukturze hipertekstowej. Wraz z rozpoczęciem właściwej rozgrywki w obszarze gry pojawiają się trzy, istotne dla omawianego zagadnienia, rodzaje kart. Karty aktów, tajemnic i lokalizacji. Dwa pierwsze rodzaje kart reprezentują kolejno postępy graczy (karty aktów) oraz postępy sił ciemności (karty tajemnic). Każdy scenariusz dysponuje własnymi unikatowymi taliami. Są one tak naprawdę kolejnymi łańcuchami leksji - każda z tych kart zawiera: tytuł, fragment tekstu fabularnego, łącze i wymagania konieczne, by móc łącze uruchomić. Przykładowy zapis elementów tekstowych z karty aktów:

\section{Akt 2a. Nieznajomy}

Tajemniczy nieznajomy z „Króla w Żółci” może wiedzieć coś na temat tego, co stało sie podczas antraktu. Musisz go znaleźć i przestuchać, jeśli masz poznać prawdę. 
Cel - Kiedy Mężczyzna w bladej masce miałby zostać odrzucony z gry, talia aktów postępuje ${ }^{60}$.

Postęp talii aktów oznacza przewrócenie karty na drugą stronę, czyli w tym wypadku przejście do leksji „Akt 2b. Miasto w płomieniach”, gdzie gracze znów przeczytają - dłuższy tym razem - fragment fabularny, będący nagrodą za wysiłki, następnie opis zmian w strukturze ludycznej (np. umieszczenie potwora w danym miejscu, odkrycie nowych miejsc etc.) i kolejne łącze (np. „Talia aktów postępuje do Aktu 3a”). Nawigowanie po tym łańcuchu leksji i odkrywanie jego kolejnych fragmentów jest zależne od wysiłków graczy muszą oni osiągać konkretne cele, by móc przejść do kolejnego ogniwa. Talia tajemnic działa tak samo z jedną różnicą: zazwyczaj przejście do kolejnej leksji następuje po upływie czasu, to znaczy po wykonaniu przez graczy określonej liczby tur. Ostatnie leksje w obu łańcuchach kierują graczy do odpowiednich leksji końcowych (np. „Zakończenie 1”, „Zakończenie 2”), znajdujących się w instrukcji załączonej do scenariusza. Ogniwo „Zakończenie” połączone z talią aktów ma - w aspekcie ludycznym - pozytywne skutki dla gracza i reprezentuje jego zwycięstwo w danym scenariuszu. Analogicznie dotarcie do leksji „Zakończenie” powiązanej z talią tajemnic każe odczytać graczom fragment narracji o skutkach ich niepowodzenia i sprawia, że kolejne scenariusze w tej kampanii będą trochę trudniejsze. Ciekawe jest to, że postęp talii aktów i talii tajemnic się nie wyklucza (jedynie przeczytanie wszystkich leksji z obu talii jest niemożliwe, gdyż ostatnia leksja w każdej z tych talii od razu kieruje do zakończenia), więc opowieść będzie się ciągle zmieniać, a ich wzajemna relacja nie jest możliwa do ujęcia w prostej drzewiastej strukturze. Warto tutaj zauważyć jedną, anegdotyczną, ciekawostkę. Według Pisarskiego twórcy literackiego hipertekstu będą łamać zasady ciągłości i koherencji, aby osiągnąć zamierzony efekt artystyczny ${ }^{61}$ - skutkiem nagłego zerwania z przejrzystymi zasadami nawigacji po hipertekście może być wzbudzenie u odbiorcy poczucia zagubienia. W Horrorze w Arkham można natrafić również na podobne zabiegi. I tak, w drugim scenariuszu, Ostatni Król na karcie „Akt 1a. Odkrywanie prawdy" nie znajduje się informacja o kolejnej leksji, do której fragment miałby odsyłać, ani tym bardziej o wymaganiach, jakie gracze muszą spełnić. Zdezorientowany gracz, wiedząc, że zazwyczaj połączone leksje znajdowały się na drugiej stronie kart aktów, w pewnym momencie odwróci kartę, żeby zobaczyć, co się znajduje na jej rewersie (być może podejrzewając, że w scenariuszu jest błąd). O ile ruch taki jest niedozwolony (gracze nie mają prawa czytać leksji, do których nie zostali skierowani), o tyle gry planszowe

\footnotetext{
${ }^{60}$ Horror w Arkham: Gra karciana. Szlak do Carcosy, Galakta 2017.

${ }^{61}$ M. Pisarski, Xanadu. Hipertekstowe przemiany..., s. 54.
} 
są ograniczonym systemem, którego elementami można dowolnie manipulować - nic nie może powstrzymać ciekawego gracza przed odwróceniem karty. Gdy to uczyni, to jego oczom ukaże się następująca informacja:

Akt $1 \mathrm{~b} \ldots$ ?

- Szaleństwo rzeczownik n III.

- Stan choroby umysłowej, zwłaszcza poważnej.

- Ekstremalnie nierozsądne zachowanie.

- Stan impulsywnych lub chaotycznych działań.

- Dlaczego patrzysz na tę stronę?

- Nie ma powodu, żeby odwracać na Akt $1 b$.

- Odwróć na Akt $1 a^{62}$.

Doświadczenie postaci gry, a więc mierzenie się z niezrozumianym szaleństwem, wykracza poza samą narrację (opowieść o niezrozumiałej istocie), poza aspekt ludyczny (w grze stan zdrowia psychicznego to pula zdrowia, której utrata kończy się popadnięciem w obłęd i przegraną) i udziela się samemu graczowi, burząc tym samym czwartą ścianę i dając mu do zrozumienia, że gra jest świadoma własnej specyfiki jako systemu transmedialnego („Nie ma powodu, żeby odwracać na Akt 1b"). Takich przykładów jest więcej, warto więc zasygnalizować ich obecność.

Wspominaliśmy o trzech istotnych typach kart: aktów, tajemnic i lokalizacji. Przyjrzyjmy się teraz tym ostatnim. To one odgrywają rolę planszy, a więc - jak pisały Sullivan i Salter - „przestrzennej metafory”63. Gracze, wykonując akcję ruchu, mogą przemieścić się do miejsc połączonych z obecną lokalizacją. Na karcie lokalizacji, poza grafiką przedstawiającą dane miejsce, znajduje się nazwa (np.: „Dziedziniec”), opis służący budowaniu narracji (np.: „Ulga, którą czujesz po opuszczeniu budynku, szybko zmienia się w grozę. $Z$ dachu wpatrują się w ciebie dziesiątki żółtych oczu, a w chmurach majaczą złowrogo jakieś dziwne kształty"), tekst istotny z punktu widzenia mechaniki gry (np.: „Wymuszony: - Po tym, jak wejdziesz na dziedziniec: odrzuć wierzchnią kartę z talii spotkań. Jeśli dana karta jest wrogiem, dobierz ją"), wartości numeryczne kart (liczba możliwych do znalezienia wska-

${ }^{62}$ Horror w Arkham: Gra karciana. Szlak...

${ }^{63}$ A. Sullivan, A. Salter, op.cit., s. 2. 
zówek i trudność wykonywanego testu), informacje o tym, czy wymagane jest spełnienie jakiegoś warunku, żeby się tu dostać (np. znalezienie klucza) $\mathrm{i}$ - przedstawiona w sposób ikoniczny - informacja o tym, z jakimi innymi lokalizacjami łączy się to miejsce (np.: z foyer, przedsionkiem, altanką). Gracze mogą poruszać się tylko między połączonymi lokalizacjami. Czym więc są lokalizacje? Wplecionymi w trzon samej rozgrywki leksjami hipertekstu. Ogniwami, których relacji nie da się przedstawić za pomocą drzewka, a jedynie za pomocą sieci. Gracz może nie tylko przechodzić między połączonymi pomieszczeniami w dowolnym kierunku (z foyer do dziedzińca i z dziedzińca do foyer), ale także może budować różne ścieżki: idąc w jedną stronę, może ominąć kuchnię, ale zatrzymać się w niej, gdy wraca inną drogą. Co równie ważne, w sieciowym modelu hipertekstu jedną z podstawowych metod jest powtarzanie tych samych leksji, lecz w zmienionym kontekście ${ }^{64}$. To samo następuje w Horrorze w Arkham, gdy gracz musi wrócić do danej lokalizacji, na przykład na dziedziniec, gdyż przezeń prowadzi droga do nowo odkrytego miejsca, albo gdy ucieka przed potworem. Trzeba też pamiętać, że lokalizacje potrafią również odsyłać do innych łańcuchów leksji: niektóre z nich łączą się z leksjami typu ,akt” lub ,zakończenie”. Przykładowo: bohater może zdecydować się uciec z obszaru gry. W scenariuszu Zgromadzenie badacze znajdujący się w lokalizacji „hol”, mogą wykonać akcję ruchu, żeby odczytać następujący tekst: „,Tego już za wiele! W panice wybiegasz przez drzwi wejściowe” i zostać odesłanym do odpowiedniego „Zakończenia” - innego niż to, które by odczytali, wygrywając lub przegrywając scenariusz. Horror w Arkham jawi się więc jako połączenie dwóch struktur hipertekstowych: model osiowy, na którym oparty został główny trzon rozgrywki (przeplatające się łańcuchy leksji „Akt x” i ,Tajemnica x” oraz nawigowanie po lokalizacjach), jest „otoczony" hipertekstami drzewiastymi, po których gracze nawigują przed rozpoczęciem rozgrywki (,Wprowadzenia” i „Przygotowania”) i po zakończeniu („Zakończenia”). Dodajmy, że struktura ta jest właściwa dla jednego scenariusza, natomiast na każdą kampanię składa się osiem scenariuszy, na których przebieg mają wpływ decyzje podjęte w poprzednich. Horror w Arkham może być więc traktowany jako niezwykle rozbudowany system hipertekstowy, po którym aspekt ludyczny gry umożliwia nawigowanie (rozgrywka jest więc, gdy spojrzy się tylko z tej perspektywy, odpowiednikiem klikania w łącza).

Pozostaje odpowiedzieć jeszcze na pytanie, jak powstała w ten sposób narracja wypada na tle innych - klasycznych - utworów przynależących do tego samego gatunku. Robert Dudziński, analizujący strategie adaptowania twórczości Lovecrafta na potrzeby gier, zauważa, że czerpią one z dwóch poetyk: kryminalnej (fabułę organizuje schemat śledztwa) i przygodowej (piętrzenie przed postaciami graczy kolejnych wyzwań, którym muszą one

${ }^{64}$ M. Pisarski, Xanadu. Hipertekstowe przemiany..., s. 213, 220-221. 
stawić czoła ${ }^{65}$. Zdaniem badacza twórcy gier muszą jednocześnie „umożliwić graczom interaktywną rozgrywkę oraz dać pewien mechaniczny ekwiwalent charakterystycznego dla opowiadań Lovecrafta fatalizmu i poczucia osaczenia" ${ }^{\prime 66}$. Z tego powodu możliwości narracyjne gier są nierzadko ograniczone, o czym zresztą pisał Arnaudo. Badacze nie zauważają jednak, że owo ograniczenie jest dwustronne: liniowy, nieergodyczny tekst powieści też nie jest w stanie zbudować takiej narracji, jak gra planszowa. To właśnie ergodyczność dzieła, jego skrajna interaktywność i nieprzewidywalność umożliwiają stworzenie takiego horroru, w którym gracz (w przeciwieństwie do pasywnego czytelnika) nie może się ukryć za plecami postaci i jedynie biernie obserwować wydarzenia. Nie dowie się, co znajduje się na poddaszu, z którego ścieka krew, jeżeli sam (poprzez wykorzystanie odpowiednich mechanik oczywiście) się tam nie wybierze. Również mechanika postępującej talii tajemnic, reprezentującej uciekający czas, może wzbudzić u gracza większy niepokój i nerwowość niż pojawiająca się w tradycyjnej powieści informacja o wyścigu z czasem.

\section{Zakończenie}

Choć gry planszowe i powieści hipertekstowe nie są ze sobą tożsame, to jednak dzięki analizie tych drugich dużo łatwiejsze staje się zrozumienie budowy tych pierwszych. Spojrzenie na grę planszową jako właśnie na literaturę, w której tekst jest wplątany w skomplikowaną sieć relacji nie tylko ze sobą samym, ale także z obrazem, dźwiękiem, a wreszcie - aspektami ludycznymi gry, wydaje się podsuwać literaturoznawstwu nowe pole badawcze. Pole, w którym tekst zaczyna być rozumiany jako złożona interakcja między graczem a grą. Powtórzmy: obserwacja podobieństw między powieścią hipertekstową a grą planszową zorientowaną na narrację to niezbyt odkrywczy, ale jednak wymagany pierwszy krok, dający jakiś punkt zaczepienia i pozwalający na dalsze badania, wzbogacone o refleksję nad transmedialnym charakterem takiego dzieła.

${ }^{65}$ R. Dudziński, Gra z niewyrażalnym strachem. Strategia adaptowania twórczości Howarda Phillipsa Lovecrafta na potrzeby gier [w:] Gry fabularne. Kultura - praktyki konteksty, red. R. Dudziński, A. Wróblewska, Wrocław 2016, s. 58-60.

${ }^{66}$ Ibidem, s. 62. 


\section{Bibliografia}

Aarseth E.J., Cybertekst: Perspektywy literatury ergodycznej. Wstęp: Literatura ergodyczna, przeł. D. Sikora, M. Pisarski, ,Techsty” 2006, nr 2, http://techsty.art.pl/ magazyn2/artykuly/aarseth_cybertekst.html [dostęp: 10.01.2020].

Arnaudo M., Storytelling in the Modern Board Game: Narrative Trends from the Late 1960s to Today, Jefferson, NC 2018.

Bolter J.D., Writing Space. Computers, Hypertext, and the Remediation of Print, Hillsdale, NJ 1991.

Dovey J., Kennedy H.W., Kultura gier komputerowych, przeł. T. Macios, A. Oksiuta, Kraków 2011.

Dudziński R., Gra z niewyrażalnym strachem. Strategia adaptowania twórczości Howarda Phillipsa Lovecrafta na potrzeby gier [w:] Gry fabularne. Kultura-praktyki - konteksty, red. R. Dudziński, A. Wróblewska, Wrocław 2016 s. 58-69.

Dyskursy gier wideo, red. M. Kłosiński, K. Maj, Kraków 2019.

Hayles K., What Cybertext Theory Can't Do, „Electronic Book Review” 2001, http://electronicbookreview.com/essay/what-cybertext-theory-cant-do/ [dostęp:10.10.2020].

Karth I., Ergodic Agency: How Play Manifests Understanding [w:] Engaging with Videogames: Play, Theory and Practice, eds. D. Stobbart, M. Evans, Leiden 2019, s. 205-216.

Kłosiński M., Hermeneutyka gier wideo. Interpretacja, immersja, utopia, Warszawa 2018.

Kubiński P., Gry wideo. Zarys poetyki, Kraków 2016.

Landow G.P., Hypertext as Collage-Writing [w:] The Digital Dialectic: New Essays on New Media, ed. P. Lunenfeld, Cambridge, MS-London 1999, s. 150-170.

Landow G.P., Hypertext. The Convergence of Contemporary Critical Theory and Technology, Baltimore, ML 1992.

McEneaney J.E., Toward a Post-Critical Theory of Hypertext, http://citeseerx.ist.psu.edu/ viewdoc/download?doi=10.1.1.25.7028\&rep=rep1\&type=pdf [dostęp: 10.10.2020].

Mochocka A., Polskie gry planszowe oparte na utworach literackich - rekonesans, „Biblioteka Postscriptum Polonistycznego” 2015, nr 5, s. 35-48.

Mochocka A., Mochocki M., Tabletop RPG: transmedialny system narracyjny [w:] Narratologia transmedialna. Teorie, praktyki, wyzwania, red. K. Kaczmarczyk, Kraków 2017, s. 337-391.

Petrowicz M., Dynamiki w grach - definicje i wykorzystanie w analizie, „Teksty Drugie" 2017, nr 3, s. 178-191.

Petrowicz M., Zasady przeciw immersji. Zaangażowanie $w$ narracje $i$ zaangażowanie $w$ system formalny gry, „Replay. The Polish Journal of Game Studies” 2015, nr 1(2), s. 35-49.

Pisarski M., Ergodyczność, http://www.techsty.art.pl/hipertekst/teoria/ergodyzm.htm [dostęp: 10.01.2020].

Pisarski M., Hipertekst a gry komputerowe, http://www.techsty.art.pl/hipertekst/gry.htm [dostęp: 10.01.2020].

Pisarski M., Poetyka: narracja w hipertekście, http://www.techsty.art.pl/hipertekst/ poetyka/narracja.htm [dostęp: 10.01.2020].

Pisarski M., Xanadu. Hipertekstowe przemiany prozy, Kraków 2013. 
Sullivan A., Salter A., A Taxonomy of Narrative-centric Board and Card Games [w:] Proceedings of the $12^{\text {th }}$ International Conference on the Foundations of Digital Games, eds. A. Canossa, C. Harteveld, J. Zhu, M. Sicart, S. Deterding, New York 2017, s. 1-10, https://dl.acm.org/citation.cfm?id=3102071.3102100 [dostęp: 10.01.2020].

Update. Teorie i praktyki kultury gier komputerowych, red. Ł. Androsiuk, Lublin 2017. Winiecka E., Czytanie jako działanie, dzieło jako zdarzenie. Czy możliwa jest poetyka literatury interaktywnej?, „Poznańskie Studia Polonistyczne. Seria Literacka” 2017, nr 30, s. 185-218.

Winiecka E., Poszerzanie pola literatury w ,, Tajemniczym płomieniu królowej Loany” Umberta Eco, „Zagadnienia Rodzajów Literackich” 2015, z. 2, s. 99-118.

\section{Ludografia}

Horror w Arkham: Gra karciana. Szlak do Carcosy, Galakta 2017. 